\title{
Dental waste characterization in the city of Ilam in 2014
}

\author{
Farzad Kazemi ${ }^{1}$, Zabihollah Yousefi ${ }^{*}$, Reza Ali Mohammadpour ${ }^{3}$ \\ ${ }^{1}$ MSc, Department of Environmental Health Engineering, Student Research Committee, Faculty of Health, Mazandaran University of \\ Medical Sciences, Sari, Iran \\ ${ }^{2}$ Professor, Department of Environmental Health Engineering, Faculty of Health, Mazandaran University of Medical Sciences, Sari, Iran \\ ${ }^{3}$ Associate Professor, Department of Biostatistics, Faculty of Health, Mazandaran University of Medical Sciences, Sari, Iran
}

\begin{abstract}
Background: Dental wastes are one of the environmental issues due to toxic and pathogenic agents such as pathological wastes, pharmaceutical and chemical etc have particular sensitivity. The aim of this study was to determine the dental waste management and related factors in the city of Ilam.

Methods: In this cross-sectional study, the studied community was all the sixteen dental clinics in Ilam. Five samples of each clinic per week (Saturday, Sunday and Wednesday) were selected. Thereafter waste sample was manually separated into 36 components and were weighed using a laboratory scale with an accuracy of $0.01 \mathrm{~g}$. Each component was weighed five times and the mean value obtained for each component was considered. Production per capita was calculated for each person. Data were analyzed using descriptive statistics, SPSS and Excel software.

Results: The per capita percent for infectious waste section was $51 \%$. The average of infectious waste is $201.13 \mathrm{~g}$. The per capita percent for chemical, pharmaceutical waste section was $36 \%$ with an average of $142.48 \mathrm{~g}$. The per capita percent for toxicity section was $13 \%$ in the dental clinics with the weighted average of $48.78 \mathrm{~g}$. According to the results of the checklist, further dental clinics have been poorly managed. Conclusion: According to the presence of various materials and different components with different characteristics in the dental wastes, the optimal management of this type of wastes should be carried out based on the specific characteristics, which include programs to reduce waste production, segregation, recycle and reuse.

Keywords: Waste management, dental waste, infectious waste, toxic waste

Citation: Kazemi F, Yousefi Z, Mohammadpour RA. Dental waste characterization in the city of Ilam in 2014. Environmental Health Engineering and Management Journal 2016; 3(3): 115-121. doi: 10.15171/ EHEM.2016.09.
\end{abstract}

Article History: Received: 19 February 2016 Accepted: 7 May 2016 ePublished: 18 May 2016

*Correspondence to:
Zabihollah Yousefi
Email: zyousefi2004@gmail.com

\section{Introduction}

The collection, transportation and disposal of waste is considered as an important and complex issue due to development of cities, increase in the number and density of population, industrialization and increase in per capita waste generation which need a regular system to implement the rules. The suitable collection and disposal of these wastes have specific importance due to their direct and indirect risks on human, animal, plants and environment (1).

On the other hand, the rapid population growth and increasing healthcare needs of human societies has led to develop and increase in the various clinics providing health services such as hospitals, clinics, public and private laboratories in the world which increases the production of medical wastes $(2,3)$. Based on Iranian Waste Management Act, all of the infectious and hazardous wastes produced by hospitals, health clinics, laboratories, dental clinics and other similar clinics are called medical wastes (4). Medical waste is assumed to be a major problem in the management of municipal solid waste in developing countries. When these wastes are mixed with municipal waste, they can create dangerous condition for the environment alongside those who are in relation with these materials (5).

Solid wastes have different qualitative and quantitative characteristics depending on the type and source of production. The awareness of the type, source and specifications of quantity and quality is important for better planning for waste management (6). Dental clinics are considered as one of the wastes production clinics (7). Dental wastes in most countries are classified as medical waste. Medical wastes are divided into two major groups namely; common and special waste. Common wastes are similar to municipal waste in terms of quality and they should be transported in accordance with the laws related to municipal solid waste. Special waste includes infectious, radioactive and chemical waste and each have certain management method (8). It is important that these types of wastes should not be mixed with municipal waste due to the spreading of chemical and biological materials which contain dangerous and pathogenic agent that ultimately lead to health and environmental risks (9). The solid or 
semi-solid material is one of the hazardous waste in the dental clinics that have the ability to create risk (10-12). A small quantity of hazardous waste is produced in dental clinics. Some of these hazardous wastes are recyclable. Hazardous dental wastes include amalgam fillings, $x$-ray film and lead foil, residues of drugs and unused chemicals (13). It is also possible that the dental clinics participate in air pollution through the water spray system as well as by blood and infected tissues. The air pollution can be in the form of aerosol or mist (14). Mercury as a heavy metal included in amalgam can lead to environmental contamination. Improper disposal of amalgam waste in dental clinics and centers can lead to environmental exposure to mercury which can have nephrotoxic and neurotoxic effects. Gastrointestinal, respiratory, immune and renal systems can be affected by mercury in amalgam waste.

The solid waste management, especially hazardous wastes, is based on the prevention and reduction of waste production, the methods which are eco-friendly and are able to ensure the health of staff working in these clinics. Lack of attention on waste management has brought dangers and irreparable damages for the staff and patients. The most important work in the field of dental waste management is to prevent the mixing of all the components, because the components of dental wastes have different characteristics and the management method should be carried out based on these characteristics (15). Thus, proper and hygienic monitoring and management on how to collect, store, transport and dispose hazardous wastes is important in order to protect the health of patients and practitioners (dentists, nurses and medical and non-medical staff) as well as referrals to dental clinics. In this study, dental waste management and the related factors were discussed in the city of Ilam in 2014. Moreover, this study has investigated the description of current situation and has carried out a detailed study on dental wastes for future planning and correct optimized management.

\section{Methods}

In this study, the studied population was all the sixteen dental clinics of Ilam (five public and 11 private) which were selected according to a list provided by medical deputy which were still active during the study period and had the necessary cooperation in the field of data collection. Each sampling was carried out at the end of working day of clinics and five samples were obtained from each clinic in three days (Saturday, Monday and Wednesday) per week. The sampling was carried out in the weeks when there were no closure and for days between Saturdays to Wednesdays. This cross-sectional study was carried out from December 2014 to February 2015. Prior to sampling, the dentists and their assistants were notified about this study. Based on World Health Organization guideline for medical waste management in developing countries (World Health Organization, 2001), a questionnaire with 54 questions were designed. Interviews with dentists and also field consideration were carried out to collect data. The collected samples were analyzed after transferring to an appropriate location. The special color-coded plastic containers were used to separate and collect each type of waste from different parts of the clinics. The common waste were collected and separated in orange plastic containers while the infectious waste with sharp objects and chemical and pharmaceutical waste were separated in safety box and brown containers, respectively and were weighed. The canvas gloves, boots, overalls and special pants for the analysis of waste were used in this study and vaccination against diseases such as tetanus, Hepatitis $b$ and $\mathrm{c}$ were carried out for collecting and weighing workers. The samples should be physically analyzed up to $3 \mathrm{~h}$ after sampling. The accuracy of digital laboratory carriage scales (model EK120A) utilized in this study was $0.1 \mathrm{~g}$. At first, the waste samples were manually separated into 36 components and were weighed. Each component was weighed five times, and the average value was calculated for each component. The obtained value represents the amount of various components of waste produced at the end of the working day of the clinic. The number of patients per working day was determined in each clinic. The per capita wastes generated were determined according to the number of patients per working day and total amount of waste produced. The collected data were analyzed using Excel software. Moreover, the per capita waste generation of each patient in any working day was obtained by dividing the amount of daily waste produced by the number patients referred in working day. In the next stage, the average daily production of various components of waste in each office was achieved by calculating the average of obtained values from 5 days sampling in each clinic.

A check list containing 45 questions were used in order to evaluate the management method of each clinic. Each of the questions had a point between 0 and 2. These obtained points were multiplied in given weight related to that points to calculate the certain number which can be assessed as follows: Good: 130-172, Average: 87-129, Weak: 44-86, Unacceptable: 0-43.

\section{Results}

Based on the points obtained from the checklist, the highest poor management in the office is related to lack of attention to eliminate the risk of infectious waste at the clinic. Other poor management factors can be expressed as follows: lack of dental amalgam recycling, fixer and developer drugs, x-ray films and its lead coatings, mercury leakage and improper storage location of wastes. Based on the results of the checklist, most of the dental clinics are faced with management deficiencies.

Table 1 shows the different components of infectious waste produced in dental clinics based on services provided (restoration, dental extraction, removal of calculus, endodontic therapy, orthodontic and implant and surgery). The greatest waste among all services provided in latex and plastic gloves was related to suture needles and its thread except for surgery which has the maximum amount in this case. The highest amount per capita for each patient was 64.43 and $44.15 \mathrm{~g}$ for dental extraction, 
Table 1. Infectious waste components in dental clinics on the basis of services provided (g)

\begin{tabular}{|c|c|c|c|c|c|}
\hline $\begin{array}{l}\text { Components of infectious wastes in } \\
\text { dental clinics }\end{array}$ & Restoration & $\begin{array}{l}\text { Dental extraction, } \\
\text { removal of calculus }\end{array}$ & $\begin{array}{l}\text { Endodontic } \\
\text { therapy }\end{array}$ & $\begin{array}{l}\text { Orthodontic and } \\
\text { Prosthesis }\end{array}$ & Surgery \\
\hline Paper napkins stained with blood & 10.78 & 150.1 & 18.1 & 8.58 & 18.63 \\
\hline Paper napkins contaminated with saliva & 8.54 & 84.7 & 7.3 & 18.6 & 11.62 \\
\hline Gauze contaminated with blood & & 353.8 & 23.56 & 53.4 & 164.42 \\
\hline Gauze contaminated with saliva & & 234.65 & 44.32 & 64.32 & 58.54 \\
\hline Cotton contaminated with blood & 34.43 & & 28.23 & & \\
\hline Cotton contaminated with saliva & 17.43 & 65.5 & 17.86 & & \\
\hline Dental roll contaminated with blood & 7.4 & 75.43 & 8.65 & 15.43 & \\
\hline Dental roll contaminated with saliva & 13.1 & 123.32 & 14.2 & 24.12 & \\
\hline Nylon gloves & 54.22 & 362.67 & 64.43 & 73.92 & 64.31 \\
\hline Latex gloves & 68.85 & 593.21 & 98.15 & 113.65 & 118.63 \\
\hline Plastic syringes & & 267.43 & 33.43 & 55.1 & 96.5 \\
\hline Suction head & 14.42 & 109.91 & 9.73 & 17.83 & 23.1 \\
\hline Extracted teeth & & 312.95 & & & \\
\hline Absolang & 11.43 & 67.43 & 8.48 & 24.26 & 14.54 \\
\hline Dental crowns & & 64.86 & & & \\
\hline Matrix tape & 6 & & 1.14 & 0.94 & \\
\hline Air spray coverage & 2.21 & 6.72 & 2.37 & 5.94 & \\
\hline Orthodontic wire & & & & 14.41 & \\
\hline The injection and washing needle & 11.71 & 77.37 & 8.21 & 6.77 & 13.97 \\
\hline Suture needles and its thread & & & & & 252.82 \\
\hline Gutta-percha & & & 33.43 & & \\
\hline Surgical Blade & & & & 43.52 & 61.87 \\
\hline Disposable plastic cover & 26.79 & 78.51 & 19.95 & 21.9 & 43.82 \\
\hline Total & 287.31 & 3028.56 & 441.54 & 562.69 & 942.77 \\
\hline The number of patients & 19 & 47 & 10 & 16 & 30 \\
\hline Per capita of patient & 15.12 & 64.43 & 44.15 & 35.16 & 31.42 \\
\hline
\end{tabular}

removal of calculus and endodontic therapy, respectively. The least amount was related to restoration which was equal to $15.12 \mathrm{~g}$.

Table 2 shows various components of toxic dental waste of the dental clinics based on different services (restoration, dental extraction, removal of calculus, endodontic therapy, orthodontic and implant and surgery). The roll contaminated with mercury is the only waste generated in orthodontics and dental prosthesis and $\mathrm{x}$-ray films and its lead coatings are related to surgery which is the higher waste in dental extraction, removal of calculus, restoration, and endodontic therapy too. The dental amalgam and material contaminated with dental amalgam has the highest amount in restoration, dental extraction, removal of calculus, and endodontic therapy.

The highest amounts per capita for each patient were related to endodontic therapy (24.87 g) and restoration (11.58 g). The least amount was obtained in orthodontics and prosthetics (1.02 g).

Table 3 presents the various components of the chemical, pharmaceutical waste in dental clinics based on the services provided. Except for orthodontics and prosthetics that has more than $96 \%$ of waste allocated to the sector, the Karpool constitutes all of the waste in the remaining cases.

The highest amounts per capita for each patient were related to orthodontics and Prosthesis (132.67 g) and endodontic therapy $(2.43 \mathrm{~g})$. The least amount was observed in restoration $(0.647 \mathrm{~g})$.
Figure 1 indicates the average percentage and quantity of dental wastes components in Ilam city. The highest values were related to infection (62\%), chemical-pharmaceutical (27\%) and toxic (11\%).

Figure 2 illustrates the per capita infectious waste, chemical-pharmaceutical, the total toxic waste generated in the dental clinics for each person. The percent per capita for infectious waste was $51 \%$. The average of per capita infectious waste was $201.13 \mathrm{~g}$.

The percent per capita chemical-pharmaceutical for dental clinics was 36\%. Average per capita chemical-pharmaceutical was $142.48 \mathrm{~g}$.

Percent per capita for toxic in the office was $13 \%$ with an average weight of $48.78 \mathrm{~g}$.

Figure 3 shows the total waste produced in dental clinics based on services (restoration, dental extraction and removal of calculus, endodontic therapy, orthodontic and implant and surgery). As can be seen, the highest waste produced is related to dental extraction, removal of calculus but the least was related to endodontic therapy and restoration.

\section{Discussion}

In this study, the lack of mercury and amalgam recycling was found to be as one of the main problems related to poor management in all dental clinics and the units of these clinics, which is in accordance (based on checklist) with other studies carried out in different cities of Iran such as Sari (16), Qaemshahr, Hamadan (17) as well as re- 
Table 2. Various components of toxic waste in dental office based on the services provided $(\mathrm{g})$

\begin{tabular}{|c|c|c|c|c|c|}
\hline Toxic waste & Restoration & $\begin{array}{l}\text { Dental extraction, } \\
\text { Removal of calculus }\end{array}$ & $\begin{array}{l}\text { Endodontic } \\
\text { therapy }\end{array}$ & $\begin{array}{l}\text { Orthodontic and } \\
\text { implant }\end{array}$ & Surgery \\
\hline Paper napkins stained with amalgam & 47.1 & 41.23 & 9.2 & & \\
\hline Gauze contaminated with amalgam & 70.73 & 97.84 & 17.43 & & \\
\hline Cotton contaminated with amalgam & 6.14 & 16.23 & 4.64 & & \\
\hline Dental roll contaminated with amalgam & 9.25 & 24.28 & 5.16 & 16.43 & \\
\hline Radiography film coating with lead foil & 58.71 & 63.61 & 179.93 & & 77.83 \\
\hline Radiography film & 1.2 & 3.45 & 14.87 & & 4.96 \\
\hline Amalgam particles & 26.97 & 167.87 & 17.54 & & \\
\hline Total & 220.1 & 414.51 & 248.77 & 16.43 & 82.79 \\
\hline The number of patients & 19 & 47 & 10 & 16 & 30 \\
\hline Per capita of patient & 11.58 & 8.81 & 24.87 & 1.02 & 2.75 \\
\hline
\end{tabular}

Table 3. Various components of the chemical, pharmaceutical waste dental office on the basis of services provided ( $\mathrm{g}$ )

\begin{tabular}{lccccc}
\hline Pharmaceutical waste & Restoration & Dental extraction, Removal of calculus & Endodontic therapy & Orthodontic and implant & Surgery \\
\hline Molding dough & & & 24.3 & 2100.96 \\
Karpool & 12.31 & 44.18 & 24.3 & 21.91 \\
Total & 12.31 & 44.18 & 10 & 2122.87 \\
The number of patients & 19 & 47.27 & 16 & 30 \\
Per capita of patient & 0.647 & 0.94 & 2.43 & 132.67 \\
\hline
\end{tabular}

search carried out in Palestine (18), nevertheless, the several studies carried out in Sweden (19), the United States $(20)$ and India $(21,22)$ indicated the recycling of amalgam. In this study, the dental clinics did not carry out any safety measure on infectious waste. Treasure and Treasure (23) conducted a study in New Zealand with the questionnaire. The results from 767 filled questionnaires showed that $56.4 \%$ of dentists wrapped the swab contaminated with blood on the paper and threw them in the trash. A $24.4 \%$ of contaminated waste and sharp materials are discharged in household waste collection containers (23). One of the main causes of improved management in developed countries is the awareness of dentists on the policy of waste management (22). Germany has also mandated that all dentistry should have a dental amalgam separation and removal with efficiency of at least $95 \%$ (24). The management level and recycling in dental clinics and other clinics can be improved by adopting laws, training classes and

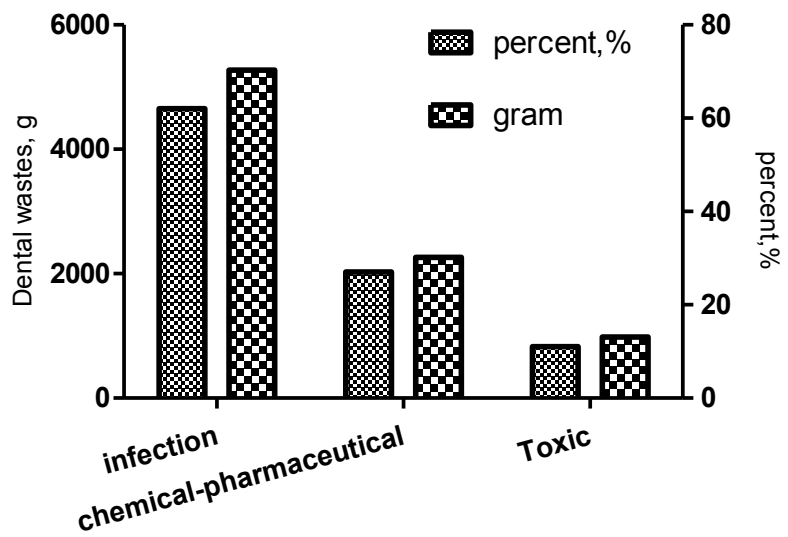

Type of components in dental wastes

Figure 1. Average percentage and gram of dental wastes components in Ilam city. providing conditions. In a study carried out at the University of Sydney, Australia in 1997 to evaluate the general condition of dental solid waste, it was determined that occupational health and safety equipment and containers for the collection of sharp instruments should be considered for this area. A 91\% of all infectious waste was constituted with items such as gloves, masks and protective coatings form. The radiographic processing was disposed to sewer in 3 cases of the 10 (25). The fixer liquid along with developer solution are commonly utilized for radiology in the mouth and teeth where the fixer liquid is classified as hazardous material due to its high concentration of silver and it should not be directly discharged into the sewer system or the trash. Silver recycling is the best way to manage it (15); while, it was observed that this method was used for only few units of the clinics in this study to manage the fixer. The study used only $6.5 \%$ of dental clinics in the city of Surrey due to their recycling. Barafrashtehpour et al

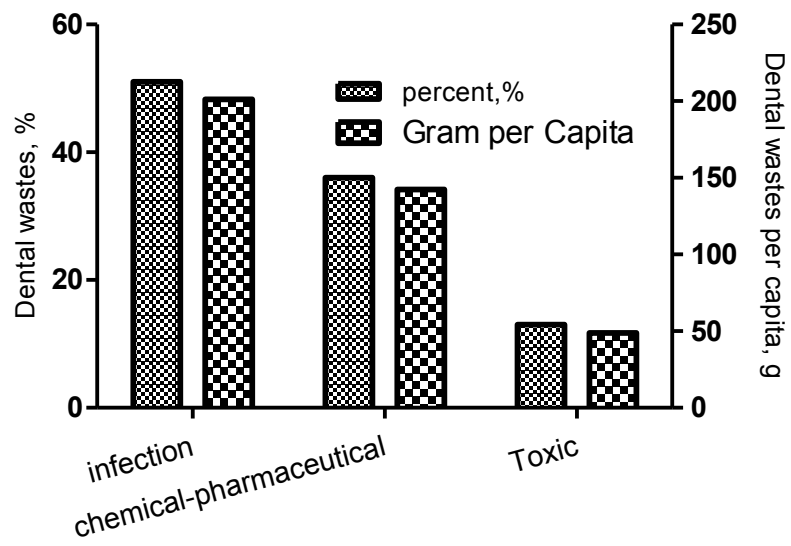

Figure 2. Average percentage and gram of dental wastes components per capita in llam city. 


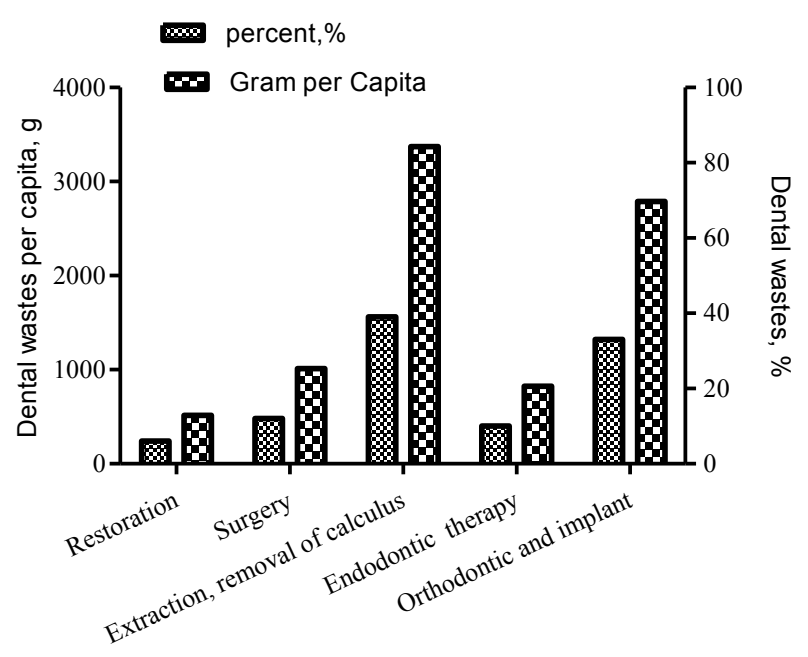

Figure 3. Waste production at the clinic based on different services ( $g$ and percent).

has found that the recycling was only performed in 5.6\% of clinics (15). The results of another study have also revealed that there was no plan to reduce production in $64 \%$ of dental wastes. The waste segregation has performed in $83 \%$ office. A $90 \%$ of dental amalgam was directly released into the sewer system. The fixer was discharged into toilet and sewer system in $90 \%$ of the dental clinics. The use of safety box was the sharp objects management in 95\% dental clinics and other clinics (15). The highest per capita amount of infectious waste for each patient was related to dental extraction, removal of calculus and endodontic therapy. The least amount was observed for dental restoration (Table 1). The percentage per capita for infectious waste was $51 \%$. The average per capita infectious waste was 13/201 $\mathrm{g}$ which is the maximum amount of waste among the three studied groups of waste (Figure 2) which is consistent with the study carried out in Shiraz (26) and Ardebil (27). Thus it can be concluded that managerial models utilized for dental waste management in Iran and other countries can be applied in Ilam due to the similarity of the type and amount of waste produced in the dental setting of Ilam and other places. Nevertheless, it should be noted that the composition and amount of dental waste varied from one office to another office at different time. As earlier mentioned, the optimized management of dental wastes is not possible only by relying on a principle, but its management should be implemented with a purposeful plan and correctly modeled from the successful management used in the world (28). For example, the replacement of amalgam with safer substances can be considered as a good option to control amalgam and its risks. Today, in countries that have effective measures in this regard, the resin material is used instead of amalgam (29). Moreover, a significant portion of the waste such as paper and plastic coatings used tools, graph paper, disposable gowns of patient and others which have not come in contact with blood and infectious material and have not been contaminated can be separated from other infectious waste and be disposed with other materials such as paper, envelopes, food cover and food debris (26).

The composition and amount of solid waste in four dentistry laboratories were studied in Xanthium, Greece in 2002. These four laboratories have produced $75 \%$ of total dental waste in the state. Sampling was carried out in a period of 2 months and was divided into 3 major categories: $(a)$ infectious and potentially infectious waste, $(b)$ non-infectious toxic waste and $(c)$ household type solid waste. The maximum amount of wastes produced in these laboratories was related to infectious and potentially infectious waste (74\%) (29), which is in line with the results of our study.

In another study which was carried out in Qazvin to investigate the quantitative and qualitative effect of dental waste, the results showed that $12 \%, 1 \%, 36 \%$ and $51 \%$ of total waste produced was related to contaminated instruments, patient's tissue, sharp instrument and consumable items, respectively but these amount was $13 \%, 8 \%, 13 \%$ and $66 \%$ for contaminated instruments, patient's tissue, sharp instrument and consumable items, respectively (30) which are similar to the results of our study presented in Tables 1-3.

The average per capita for each person was $382.72 \pm 9.67$ $\mathrm{g}$ and more than $50 \%$ were infectious wastes. The study carried out in Greece by Kizlary et al (29) showed that the amount of infectious and semi-household waste was $94.7 \%$ and 3.3\%, respectively. Moreover, the rate of dental waste production was $513 \mathrm{~g}$ per person per day while the rate of infectious waste generation was about $486 \mathrm{~g}$ per person per day. The results of this study were also in accordance with that of our study.

In present study, two other groups of dental wastes such as chemical-pharmaceutical waste and toxic waste constitute $7.7 \%$ of total waste production. These two parts contain toxic elements and chemicals and some of its elements such as amalgam particles and lead foil coated radiographic films are recyclable. Generally, we can say that these two parts of the dental waste should be collected and separated according to their characteristics and sometimes considered as hazardous material. The results of this study are in agreement with the results of the study of Nabizadeh et al (17) where the amount of household, infectious, chemical-pharmaceutical and toxic waste was $91.14 \%, 2.14 \%, 6.7 \%$ and $0.02 \%$, respectively.

A study carried out in Shiraz, Southern Iran indicated that $89.1 \%$ of dental offices and clinics disposed their infectious waste with domestic waste. Standard method for the disposal of sharp objects was obtained as $60 \%$ by these centers and zero percent for their pharmaceutical and $\mathrm{x}$ ray wastes. Amalgam recycling and lead foil pockets waste manufactured by these centers were less than $10 \%(31)$.

An investigation carried out on the characteristics and management of dental wastes in Urmia, Iran, showed that 31 components were manually separated and weighted. The results showed that domestic, potentially infectious, toxic, chemical and pharmaceutical wastes were $35.46 \%$, $34.24 \%, 11.83 \%$ and $5.56 \%$, respectively (32). In dental centers in Esfahan city, the amount of infectious, non- 
infectious and domestic wastes were obtained as $45.07 \%$, $12.15 \%$ and $42.78 \%$, respectively (33).

\section{Conclusion}

Finally, it can be suggested that the training of dentists for activities related to the reduction, separation and recycling in the dental clinics can play important role in developing the dental waste management.

Nevertheless, providing guideline and criteria for collection, transportation and separating disposal of any waste sector dental medications (like household waste, potentially infectious, chemical medicinal and poisonous) seems to be necessary. Undoubtedly, the continuous and correct monitoring of the above actions is necessary to obtain best results. Due to the implementation of problems, it is recommended that the dental wastes should be classified into four groups including semi-household waste, infectious, sharp and chemical objects and be separated at site. Separation and source reduction and separate disposal of wastes can be best way to control dental wastes.

\section{Acknowledgments}

The authors are grateful to the committee of student research of Mazandaran University of Medical Sciences for their financial support. This article was extracted from the MS Project (Research project code 162 in Mazandaran University of Medical Sciences) of F. Kazemi.

\section{Ethical issues}

There were no ethical issues for conducting this article.

\section{Competing interests}

We affirm that this article is the original work of the authors and have no conflict of interest to declare.

\section{Authors' contributions}

All authors were involved in all stages of the article. On behalf of the co-authors, the corresponding author bears full responsibility for this submission.

\section{References}

1. Center for Disease Control and Prevention, Healthcare Infection Control Practices Advisory Committee (HICPAC). Guidelines for Environmental Infection Control in Healthcare Facilities. 2001. Available from: http://www. cdc.gov/hicpac/pdf/guidelines/eic_in_HCF_03.pdf.

2. Tchobanoglous $G$, Theisen $H$, Vigil SA. Integrated Solid Waste Management: Engineering Principles and Management Issues. New York: McGraw-Hill; 1996.

3. Omrani G, Alavi N. Hospital Solid Waste. Tehran: Tehran University Publication; 2008. [In Persian].

4. Department of Environmental Iran.Waste Management ACT. Departmentof Environmental Publications; 2004.

5. Tsakona M, Anagnostopoulou E, Gidarakos E. Hospital waste management and toxicity evaluation: a case study. Waste Manag 2007; 27(7): 912-20.

6. Birpinar ME, Bilgili MS, Erdoğan T. Medical waste management in Turkey: a case study of Istanbul. Waste Manag 2009; 29(1): 445-8.

7. Wong KV, Kashyap R. Medical waste characterization. J
Environ Health 1994; 57(1): 19-25.

8. Green AE. Medical Waste Inciration and Pollution Prevention. New York: Springer; 1992.

9. Verma LK, Mani S, Sinha N, Rana S. Biomedical waste management in nursing homes and smaller hospitals in Delhi. Waste Manag 2008; 28(12): 2723-34.

10. Arenholt-Bindslev D. Environmental aspect of dental filling materials. Eur J Oral Sci 1998; 106(2 Pt 2): 713-20.

11. La Grega MD. Hazardous waste management. 2nd ed. New York: McGraw Hill; 2001.

12. Fan PL, McGill SL. How much waste do dentists generate? J Calif Dent Assoc 1989; 17(12): 39-40.

13. Trip L. Canada-wide standards: a pollution prevention program for dental amalgam waste. J Can Dent Assoc 2001; 67(5): 270-3.

14. ADA Council on Scientific Affairs and ADA Council on Dental Practice. Infection control recommendations for the dental office and the dental laboratory. J Am Dent Assoc 1996; 127(5): 672-80.

15. Barafrashtehpour M, Rezayi S, Alinejad A, Sadat A. Evaluation of dental wastes management In Yasouj. Thirteenth Congress of Iran Environmental Health; Kerman, Iran; 2010. [In Persian].

16. Zazoli MA, Barafrashteh Pour M, Mahdavi Y, Rostamali E. Qualitative and quantitative analysis and Dental waste management in the city of Sari, Iran. Seventh Congress of Epidemiology; Yasouj, Iran; 2013. [In Persian].

17. Nabizadeh R, Kulivand A, Jonidi Jafari A, Younesian M, Omrani GH, Evaluation of dental solid waste in Hamedan. Journal of Dental Medicine 2009; 22(1): 66-73. [In Persian].

18. Darwish RO, Al-Khatib IA. Evaluation of dental waste management in two cities in Palestine. East Mediterr Health J 2006; 12(2): 217-22.

19. Ogden GR, Bahrami M, Sivarajasingam V, Phillips G. Dental students' knowledge and compliance in cross infection control procedures at a UK dental hospital. Oral Dis 1997; 3(1): 25-30.

20. Jamie S. Reducting dental mercury discharge in Missoula, Montana: collaborative opportunites. Master of Science Environmental Studies, California; 2001.

21. Sudhakar V, Chandrashekar J. Dental health care waste disposal among private dental practices in Bangalore city, India. Int Dent J 2008; 58(1): 51-4.

22. Sushma M, Bhat S, Shetty S, Babu S. Biomedical dental waste management and awareness of waste management policy among private dental practitioners in Mangalore city, India. Tanzania Dental Journal 2010; 16(2): 39-43.

23. Treasure ET, Treasure P. An investigation of the disposal of hazardous wastes from New Zealand dental practices. Community Dent Oral Epidemiol 1997; 25(4): 328-31.

24. Koulivand A, Nbizadeh R, Joneidy A, Younesian M, Omrany G. Quantity and quality analysis and management of solid waste produced in dentistry laboratories and practical dentist office in Hamedan, 2007. Iranian Journal of Health and Environment 2009; 2(1): 36-45. [In Persian].

25. Cannata S, Bek M, Baker P, Fett M. Infection control and contaminated waste disposal practices in southern Sydney area health service dental clinics. Aust Dent J 1997; 42(3): 199-202.

26. Ghanbarian M, Majlesi M, Samaei MR. Analysis of Solid Waste Products Disposed by Dental Clinics in Shiraz. Journal of Research in Dental Sciences 2013; 10(4): 246-51. [In Persian]. 
27. Sotoudeh M, Dindra S, Merrikhi H, Talebi M, Ebrahimi S. Qualitative and quantitative analysis and Dental waste management in Ardabil city. The Third Student Congress of Ardabil University of Medical Sciences; Ardabil, Iran; 2011. [In Persian].

28. Ozbek M, Sanin FD. Astudy of dental solid waste produced in a school of dentistry in turkey. Waste Manag 2004; 24(4): $339-45$.

29. Kizlary E, Losifidis N, Voudrias E, Panagiotakopoulos D. Composition and production rate of dental solid waste in Xanthi, Greece. Waste Manag 2005; 25(6): 582-91.

30. Nafez A, Karbord A, Sharifi M, Jabari R, Abotorabi M. Qualitative and quantitativ of dental wastes in Qazvin.
Twelveth Congress of Iran Environmental Health; Tehran, Iran; 2009. [In Persian].

31. Danaei M, Karimzadeh P, Momeni M, Palenik CJ, Nayebi M, Keshavarzi V, et al. The management of dental waste in dental offices and clinics in Shiraz, Southern Iran. Int J Occup Environ Med 2014; 5(1): 18-23.

32. Koolivand A, Gholami-Borujeni F, Nourmoradi H. Investigation on the characteristics and management of dental waste in Urmia, Iran. J Mater Cycles Waste Manag 2015; 17(3): 553-9.

33. Nafez AH, Ebrahimi A, Hajian Nejad M, Bina B. Quantity and composition of produced dental solid waste in Isfahan, 2011. Int J Environ Health Eng 2014; 3: 17. 